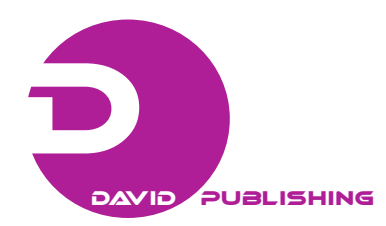

\title{
The Concept of Using the Strategic Noise Maps in Planning of Urban Space in Poland
}

\author{
Kinga Szopińska and Janusz Kwiecień \\ Department of Geomatics, Geodesy and Spatial Economy, University of Technology and Life Sciences, Bydgoszcz 85-225, Poland
}

\begin{abstract}
In the territory of Poland the manner of urban space management is defined by a planning document called LLUP (local land use plan). When analyzing the development process of Polish cities, an obvious conclusion emerges about the lack of complex studies and researches of the environment concerning the issue of acoustic climate. The procedures of development of local land use plan involve merely a general diagnosis of an environment excluding measured values of pollution, including noise levels. The main aim of this article is to introduce the issue of the influence that acoustic climate has on the urban space planning with the application of SNM (strategic noise mapping). The map enables holistic assessment of the degree to which urban areas are exposed to noise, determines its sources and forecasts variations of its levels. Preliminary research results confirmed the necessity of including noise level influence in the procedures related to urban space planning especially concerning its forecasted levels resulting from estimates of local land use plans. Applying SNM in verification of conceptual space arrangements in terms of protection against noise in the preparation of LLUP as well as their further application in the plan is a considerable advantage.
\end{abstract}

Key words: Spatial planning, environmental noise, strategic noise map.

\section{Introduction}

All disturbing and harmful sound phenomena emerging in an environment contribute to the acoustic climate of an area. In accordance with rapid development of cities, decreasing urban space as well as constantly increasing number of noise emitters, the problem of its excessive influence has become a common issue. Existence of noise in urban environments results in discomforts among inhabiting population, contributing to so called urban stress as well as negatively influencing administration of city resources [1,2]. Evaluating acoustic climate when planning territorial development is an important factor contributing to creation of urban space in a harmonious manner, with utilization of its full potential and preservation of natural environment values. The problem is reflected in the Directive 2002/49/WE of the European Parliament and the

Corresponding author: Kinga Szopińska, Ph.D. student, research fields: environment engineering, real estate management and protection of urban areas from noise. E-mail: k.szopinska@utp.edu.pl.
Council of Europe from June 25, 2005 which concerned assessing and management of noise levels in an environment. It is an obligation of all the member states of European Community to determine noise levels and indicate policies to enhance acoustic conditions as well as protection of areas of acceptable noise levels. Poland, as a member of European Community is obliged to comply with the regulations of the previously mentioned Directive.

\section{Strategic Noise Map as a Tool Applied in the Process of Acoustic Climate Assessment}

One of the actions aiming at protection against noise suggested by the Directive 2002/49/WE [3] is the SNM (strategic noise map). SNM is an averaged map of noise generated into environments by various groups of sources. It enables holistic evaluation of a level of noise exposure within an urban area, provides the possibility to determine the origins of such phenomena as well as the opportunity to prepare general prognoses of alterations of its levels. Noise map calculations are made on the basis of the database 
received from the GIS (geographical information systems) and with the use of expert computer software such as CadnaA, SoundPlan [3-5]. In Polish legal system the most fundamental legislative act regulating the issues of environmental noise is Environment Protection Law Act of April 27, 2001 as amended. According to article, 112 noise exposure protection means providing the most accurate condition of acoustic climate by maintaining the level of noise which does not exceed admissible values. In the process of preparation of SNM (strategic noise map), environmental noise may be denoted by $L_{\text {den }}$ and $L_{n i g h t}$ indicators. $L_{d e n}-\mathrm{a}$ long-term "A" noise indicator measured in $\mathrm{dB}$ (decibel) is a measure of sound pressure level [6]), estimated within 24-hour cycles of a year, considering daytime (the period between 6:00 a.m. to 6:00 p.m.), evening (from 6:00 p.m. to 10:00 p.m.) and nighttime (from 10:00 p.m. to 6:00 a.m.). $L_{\text {night }}$ - a long-term "A" noise indicator measured in $\mathrm{dB}$ estimated during night hours (from 10:00 p.m. to 6:00 a.m.). Their acceptable values in affected areas are estimated in the Directive of Ministry of Environment of June 14, 2007 of acceptable noise levels in the environment. The value of indicators is related to the origin of sound source and the purpose of a location affected (Table 1).

Article 7 of the Directive 2002/49/WE imposes the obligation to make strategic noise maps showing the situation in the preceding calendar year for agglomerations within their territories no later than-June 30, 2007-for agglomerations exceeding 250,000 inhabitants and June 30, 2012-for all agglomerations. In the directive context the term "agglomeration" means part of a territory having a population in excess of 100,000 and population density allowing a member state to consider it an urbanized area. Strategic noise maps have been prepared for all the Polish cities exceeding 250,000 inhabitants including Warszawa, Kraków, Wrocław, Poznań or Bydgoszcz. Strategic noise maps are currently under preparation by local governments of agglomerations with the population in excess of 100,000 (Fig. 1), which is firmly supported by Polish legislation, and more precisely, by article 117 of the Environment Protection Law [7, 8].

About environmental noise in the process of spatial development of polish cities, spatial planning policies are described by a system of planning documents controlled by Spatial Planning and Land Development Act of March 27, 2003. Sustainable development principle and spatial order form the basis of spatial planning efforts. As for communal local legal regulations being the support for urban development, it is the local land use plan [5]. It is an intermediate stage between strategic planning, the study of land use conditions and directions and the implementation level, where arrangements of the plan are deployed in the form of approvals to initiate developmental actions of a given investment (Fig. 2).

In a LLUP some issues are arranged, such as the purpose of a given area, location of public-purpose investments, land development conditions. The authors propose to determine land use in such a way as to be consistent with the economic needs of

Table 1 Acceptable noise level for particular groups of sources.

\begin{tabular}{|c|c|c|c|c|}
\hline \multirow{3}{*}{ Area type } & \multicolumn{4}{|c|}{ Acceptable noise level (dB) } \\
\hline & \multicolumn{2}{|c|}{ Roads or railway } & \multicolumn{2}{|c|}{$\begin{array}{l}\text { Other facilities and activities } \\
\text { being the noise sources }\end{array}$} \\
\hline & $L_{\text {den }}$ & $L_{\text {night }}$ & $L_{\text {den }}$ & $L_{\text {night }}$ \\
\hline Protected zone "A"—-spas, areas of hospitals located outside cities & 50 & 45 & 45 & 40 \\
\hline $\begin{array}{l}\text { Areas of single family dwellings, nursing homes and hospitals in cities as well } \\
\text { as residential areas for permanent and temporary inhabitants }\end{array}$ & 55 & 50 & 50 & 40 \\
\hline $\begin{array}{l}\text { Areas of multi-family residential units, homestead housing, recreational areas, } \\
\text { housing and service oriented areas }\end{array}$ & 60 & 50 & 55 & 45 \\
\hline City center zones of cities with the population exceeding 100,000 inhabitants & 65 & 55 & 55 & 45 \\
\hline
\end{tabular}




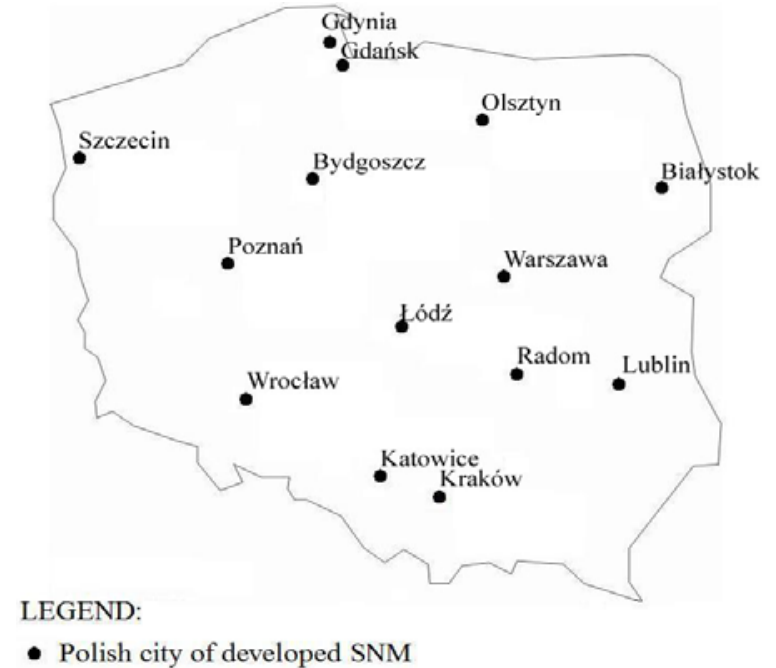

- Polish city of developed SNM

Fig. 1 Polish map of selected cities from the developed SNM.

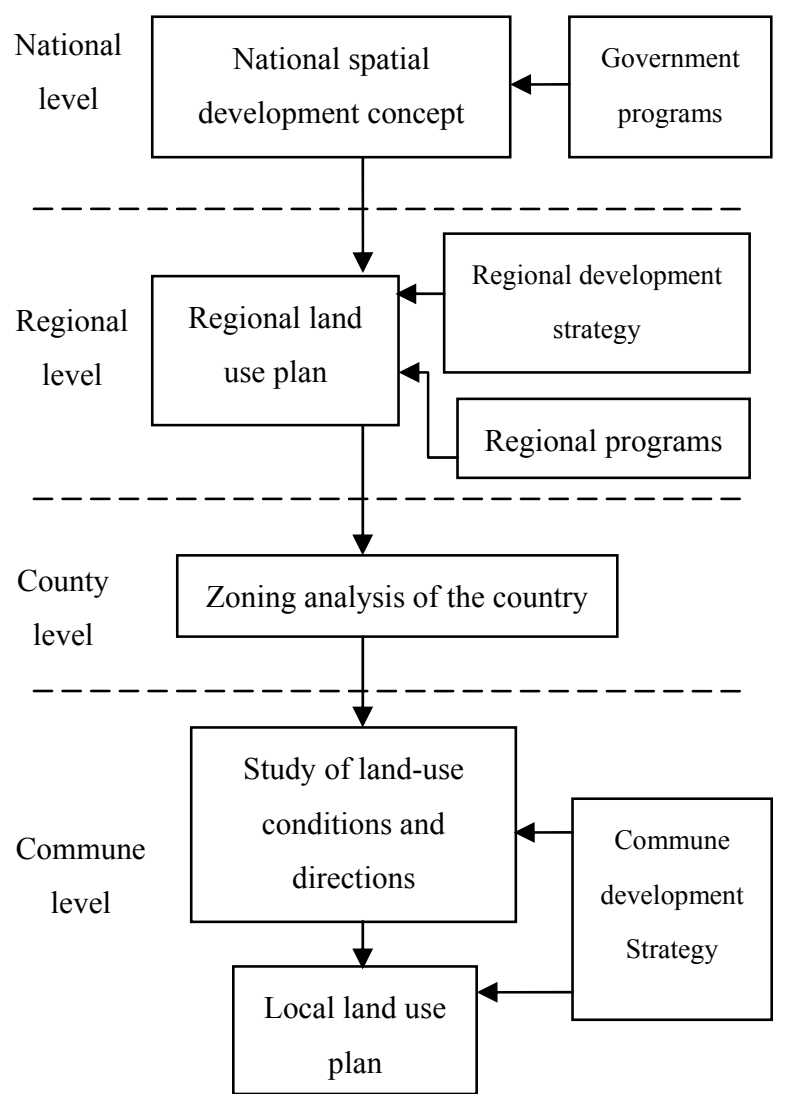

Fig. 2 The structure of spatial planning in Poland.

different fields, was known and predictable and socially acceptable to the principles of sustainable development $[9,10]$. The four major spatial planning functions are as follows: coordination, regulatory, informative and inspirational in the LLUP are implemented primarily regulatory function. Plan regulatory arrangements apply to all participants in urban planning at the commune level, which is expressed by identifying the business, resulting in the use of space. The primary role of a LLUP is to prevent conflicts and minimizing them, as well as the association of shared interests and activities of the different actors. Local land use plans are implemented within territorially administrative municipalities, and so not all municipal areas have enacted legal enactments. In Poland, only $25.6 \%$ of the country has existed a LLUP. In addition, between the provinces there is a large variation in the percentage of land, for which it is adopted local land use plan, more than $60 \%$ to only a few percent [11].

According to Article 71 of Environment Protection Law Act of April 27, 2001 along with its further changes, environmental protection issues form the basis of a local land use plan. In accordance with the act, local plans must include all the necessary solutions preventing pollution and give directions for planning to take into consideration the aspect of maintaining ecological balance and to rationally manage natural resources in relation to the need of protection from noise exposure. The requirements are fulfilled in various manners in local planning:

(1) Identifying areas of different functions and land development conditions such as noise-sensitive areas with existing acoustic standards of environmental quality. Such protected areas include: areas for residential build-up, noise-sensitive buildings such as hospitals, nursery homes, areas for spas and for buildings of permanent or temporary residence for children and minors;

(2) Defining areas of limited or restricted use including quiet areas of acceptable noise levels;

(3) Locating areas of manufacturing, warehousing or storing activities in distances which eliminate their negative influence on the environment and people. The influence is characterized by excessive levels of industrial noise. 


\section{Research Problem}

In actions related to urban space planning and especially while identifying noise-sensitive areas, assessment of noise levels of sources included in LLUP is essential for proper functioning and organization of a city [12, 13].

The local land use plan preparation procedure includes verification of existing conditions as well as identification of changes in spatial organization. The preparation stages were divided into four major phases by Cymerman [10]. Phase 0 is characterized by collecting initial input data providing information about the area. Such resources include a master map, ecophysiography as well as urban planning inventory. In Poland, ecophysiography is interdisciplinary description, which are analyzed features natural and geographic of the area for the purpose of spatial planning. The needed analysis of natural environment condition is provided by ecophysiography. Such a study includes information about current condition along with possible threats to individual environmental components including noise levels and its possible value alterations in relation to time. After assessment and verification of completion of collected initial data, phase 1 follows - analytic work. This stage deals with assessing developmental conditions on the basis of available documentations as well as identifying threats to the environment and its susceptibility to changes. Phase 2 is about creation of introductory concepts of spatial development solutions, on the basis of which a draft of a plan, forecasts of financial consequences as well as the prognosis of influence of the plan solutions on natural environment (phase 3). The main aim of the prognosis is assessment of effects implementation of LLUP. On the basis of its results, it is possible to verify the draft plan assumptions in terms of its negative influence on the environment. The prognosis preparation involves using initial data of the study of land use conditions and directions, ecophysiography and cartographic documentation. After approvals and social consultation, the project of a plan is written down in the form of a local legal act and regulations including land development and build-up parameters are formed. Phase 4 involves final works connected to introducing the local land use plan.

Currently in Poland, the procedures of developing local plans involve an environment diagnosis in form of ecophysiography and prognosis of the impact on the environment (referred to as the prognosis). In ecophysigraphy the information concerning acoustic climate of an area originate mainly from the study of land use conditions and directions and researches of reports concerning condition of natural environment (referred to as the report). The documentation includes randomly prepared acoustic analyses. The report includes sound measurements made in major cities and does not include information on noise generated by all the groups of sources. The study of land use conditions and directions contains only descriptive analyses of acoustic climate, excluding measured values. Analogical situation concerns the prognosis which does not include precise measurement of noise and its levels. All the analyses for existing condition and the target situation (with the fulfillment of the plan's conditions) have their source in additional documentation such as the study of land use conditions and directions. Therefore it must be emphasized here that no precise acoustic analyses of noise levels generated by sources listed in the plan are performed [14]. All the applied means of noise protection such as acoustic screens, location of sensitive areas and distances from noise sources do not result from precise calculation but mere interpretations of partial, hardly credible data.

The previous observations and the analysis of the previously mentioned documentation indicate the lack of complex research of environment in terms of acoustic climate for existing and forecasted conditions. Thus it has been suggested here to introduce the application of SNM in the preparation process of LLUP through the following project solutions (Fig. 3): 
(1) SNM as a credible source of information about noise levels should be included in the initial documentation of the procedure of preparation of the LLUP (Phase 0);

(2) While preparing environmental forecasts, SNM analyses must be introduced since they take into account the levels of noise originating from sources indicated by the plan (Phase 3);

(3) Once the forecast has been analyzed, it has been suggested to repeat the same procedure with the draft plan and analyze it in terms of preservation the acoustic standards for noise-sensitive areas (Phase 3).

When applying SNM the authors receive measurable noise values in decibels, which allows for clearly and easily verified conclusions for the forecasts. In the same time, it prevents the commonly applied and highly incorrect methods of identifying of applying highly inaccurate expressions concerning acoustic climate such as: high, low, strong, weak for existing conditions and probably at the same level, remaining unchanged, for a target situation, with no precise values and measurement.

\begin{tabular}{|l|l|l|}
\multicolumn{2}{|c|}{ Gathering material inputs } \\
\cline { 2 - 3 } \multicolumn{1}{|c|}{ Legislative requirement } & \multicolumn{1}{c|}{ Principles of good practice } \\
\cline { 2 - 3 } & Basic map (incl. real estate) & Urban inventory \\
Ecophysiography & Information of cultural values \\
Applications to the LLUP submitted by & Past planning studies \\
citizens and institutions & The legal status and condition of the possession \\
& SNM (existing acoustic climate) \\
\hline
\end{tabular}

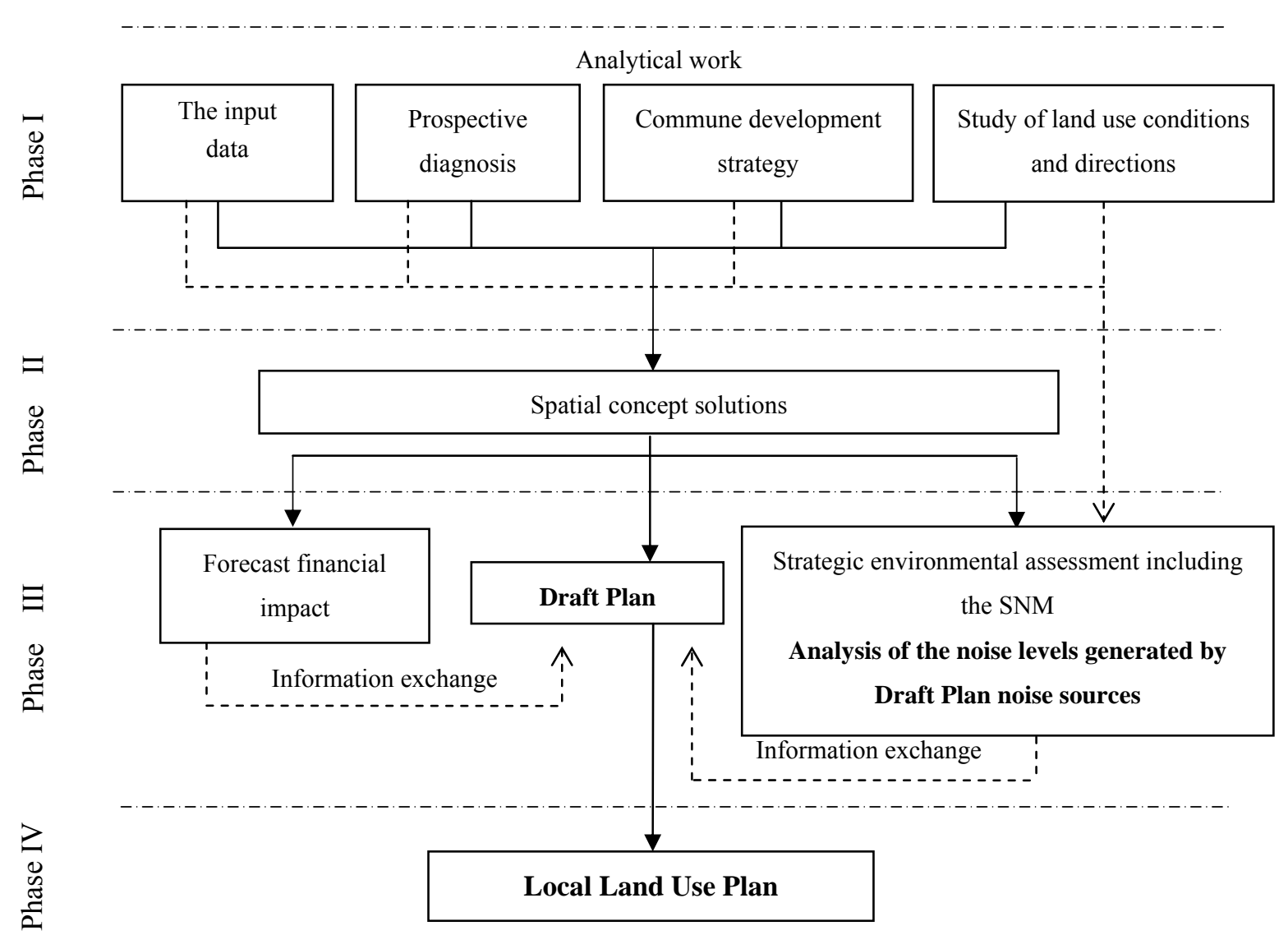

Fig. 3 Stages of LLUP including the SNM. 


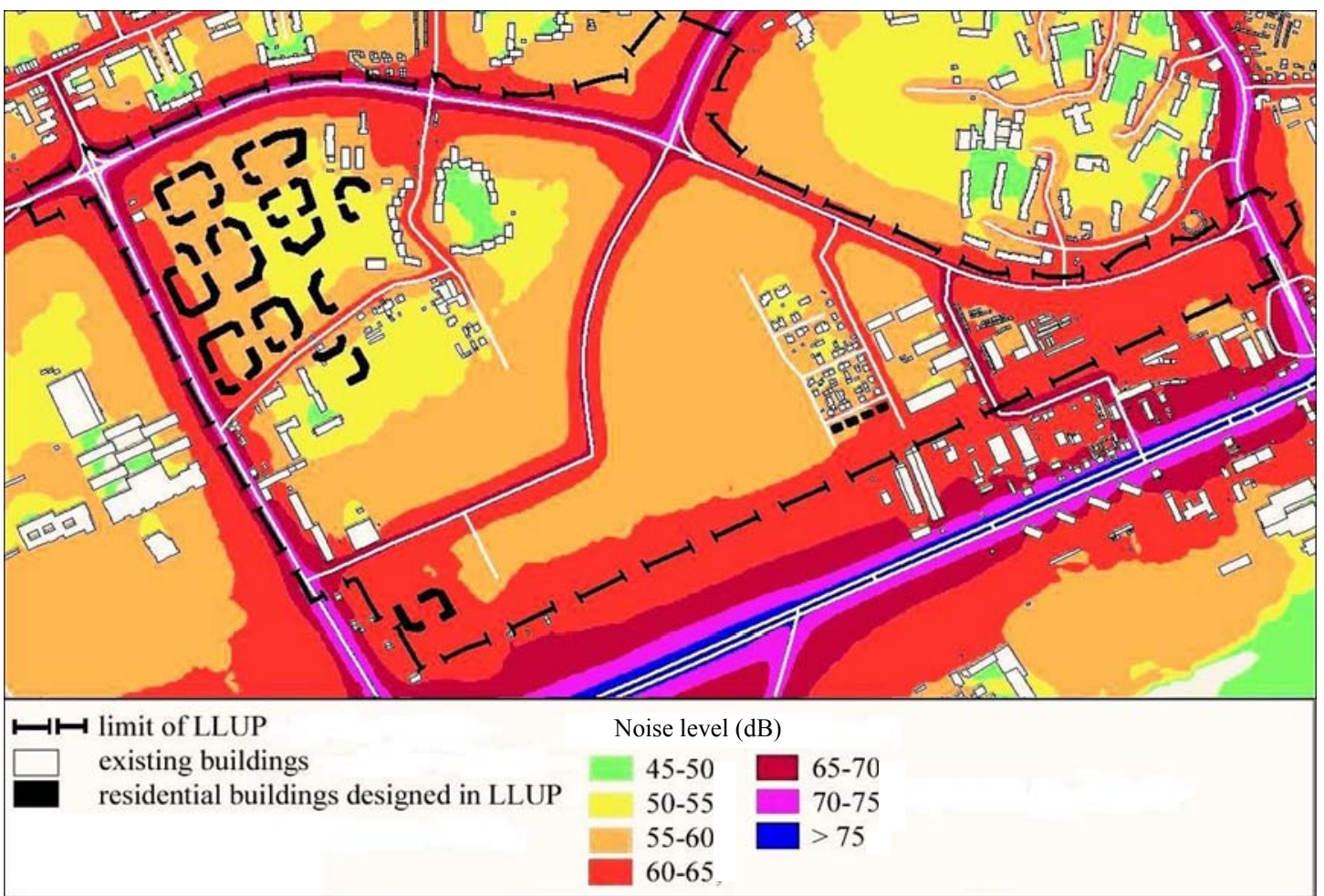

Fig. 4 Analyzed local land use plan in comparison with strategic noise map (existing level of traffic noise-noise indicator $\left.L_{d e n}\right)$.

Ever since Directive 2002/49/WE concerning development of noise strategic maps in agglomerations with the population of over 100,000 became effective, access to precise, unquestionable acoustic data has been considerably easier. Application of the new source of information in the process of creation of LLUP will allow for more precise estimation of boundaries of areas of different land development, especially sensitive areas, where according to the directive noise level must not exceed acceptable values. With such an approach in mind, SNM becomes a new tool supporting the process of developing urban space with the preservation of principles of sustainable development and spatial order.

\section{Research Area}

In actions related to urban space planning and especially while identifying noise-sensitive areas, assessment of noise levels of sources included in an LLUP is essential for proper functioning and organization of a city $[1,14]$.

The local land use plan of Akademickie-Wschód district covering the area of 94,970 hektar (hektar is a metric unit of measurement of land area -1 hektar = 2.471 acre) in Fordon unit of the city of Bydgoszcz. The area is located in the eastern part of the city in Fordon. The following is the research area selection criteria:

(1) Variety of functions and manners of area development included in the local plan. The existence of numerous areas of various development including sensitive areas such as residential areas $-25 \%$ of the plan. The remaining part is characterized by transportation areas - over $40 \%$, green areas $-25 \%$ or service infrastructure $-7.2 \%$ of the plan;

(2) Diversity of noise sources. The acoustic climate of the researched plan is characterized by different level noise sources including noise originating from roads, railway and industry. Such a diversity allows for treating the LLUP as representative for the whole city; 
(3) Exceeded values of noise levels in the neighborhood of noise-sensitive areas (residential buildings). For the of multi-family housing properties accepted road traffic noise level must not exceed 55 decibel (Fig. 4) [6];

(4) The LLUP does not include records of environment impact assessment associated with localization of isolative structures such as acoustic screens, embankments and green slopes (Fig. 4).

After thorough analysis of the material gathered with the application of an SNM in a selected local plan (Fig. 4), it has been estimated that boundaries of sensitive areas run close to noise sources, where noise level varies between 60-65 decibel, thus no acoustic standards have been maintained for the area. If urban planners had taken the system of local planning including application of SNM into consideration, the problem of excess noise level would have been eliminated at the draft planning stage before its legalization.

\section{Conclusions}

The presentation of the problem of influence of acoustic climate on urban space planning as well as presentation of stages of the preparation of LLUP in relation to the application of a strategic noise map may lead to the following conclusions:

(1) The issue of environmental noise and methods of protection against it is not sufficiently identified in the process of preparation of LLUP;

(2) The noise map is a valuable and irreplaceable source of information about noise levels and thus should be applied by urban planners in the process of urban space planning according to principles of sustainable development and spatial order;

(3) Every analysis of acoustic climate of a surrounding included in a local plan is of an intuitive character and is prepared on the basis of incomplete data. It concerns both existing and target conditions after fulfillment of the plan;

(4) SNM enables verification of conclusions included in the forecast of environment impact concerning protection against noise since it provides measurable values of its level. Consequently, it results in more precise estimation of different urban development areas and their limits, which is especially significant in terms of noise-sensitive areas where noise level requirements identified by lawmakers must be preserved;

(5) Applying SNM in verification of conceptual space arrangements in terms of protection against noise in the preparation of LLUP as well as their further application in the plan is a considerable advantage.

Preliminary research results confirmed the necessity of including noise level influence in the procedures related to urban space planning especially concerning its forecasted levels resulting from estimates of local land use plans. The changes affecting the space (and the accompanying noise) are of dynamic character, thus a necessity of constant monitoring emerges. Reliable information concerning alterations of environmental noise levels is crucial for the space participants in the process of proper investment decision making as well as for urban planners to be able to design an inhabitant-friendly city which complies with the rules of sustainable development. Full comprehension of the subject of the influence of environmental noise on urban space development requires further research and analyses. Consequently, further analyses of other Polish cities, where strategic noise maps have been prepared, are planned to be initiated along with comparative studies of the outcome with the information included in strategic noise maps prepared for the territories of Germany and Great Britain.

\section{References}

[1] J. Kwiecień, K. Szopińska, M. Sztubecka, Problem of noise protection in urban areas on the example of Bydgoszcz, Ecology and Technology 18 (4) (2010) 205-212. (in Polish)

[2] C. Yu, J. Kang, Acoustic sustainability in urban 
residential, in: 3rd International Conference on Environmental Science and Information Application Technology (ESIAT 2011), Texas, USA, 2011, pp. 471-477.

[3] D. Xie, Y. Liu, J. Chen, Mapping urban environmental noise: A land use regression method, Environmental Science and Technology 45 (17) (2011) 7358-7364.

[4] J. Stoter, H. Kluijver, Noise mapping and GIS, optimising quality and efficiency of noise effect studies, in: International Conference on Decision Making in Urban and Civil Engineering, Lyon, France, 2012.

[5] K. Szopińska, Acoustic Environment of urban space - Concept of database system GIS-SMA, Journal of the Polish Real Estate Scientific Societ 20 (1) (2012) 195-207.

[6] Z. Engel, Environmental Protection against Vibration and Noise, Polish Scientific Publishers PWN, Poland, 2001.

[7] K. Szopińska, M. Krajewska, M Bełej, Apartment market analysis considering environmental noise level in Poland, in: European Real Estate Society 19th Annual Conference, Edinburgh, Scotland, June 13-16, 2012. (in Polish)

[8] M. Krajewska, K. Szopińska, Noise level in relation to real estate prices in selected settlements in Poland, in:
FIG Working Week, Rome, Italy, 2012, pp. 6-10.

[9] M. Kistowski, Natural Conditions in Urban Planning in the Context of the Protection of Natura 2000, in: N. Ratajczyk, D. Kopcia (Eds.), Environmental Law and Investment Processes, Ziemi Łódzkiej, Łódź, 2012, pp. 117-124.

[10] R. Cymerman, Fundamentals of planning and urban design, Publisher of University Warmia and Mazury, Olsztyn, 2010.

[11] E. Czekiel-Świtalska, Selected legal and implementation issues of local planning, Space and Form 15 (2011) 289-302.

[12] B. Lebiedowska, Acoustic background and transport noise in urbanised areas: A note on the relative classification of the city soundscape, Transportation Research Part D: Transport and Environment 10 (4) (2005) 341-345.

[13] W. Paszkowski, Elements of spatial planning in designing of acoustic environment on urban areas, Management Systems in Production Engineering 3 (3) (2011) 33-35.

[14] E. Papińska, The role of ecophysiographic analyses in the spatial planning process, Technical Transactions 7 (2007) 185-190. 